\section{Commentary: The safer operation can be the more complicated one}

\author{
Meghana R. K. Helder, MD, and \\ Michael Bacharach, MD
}

In this issue of the Journal, Buditz-Lilly and colleagues ${ }^{1}$ present a very timely and interesting study discussing the potential endovascular eligibility of patients who have undergone open initial repair for type A aortic dissection. Reoperation after initial open repair for type A aortic dissections in the study was $20 \%$, and most of it was within 1 year. This number cannot be ignored, and the paradigm of "dealing with it after they survive" is shortsighted, especially if the choices made during the initial operation make a lower risk endovascular option feasible for future reoperations.

Buditz-Lilly and colleagues ${ }^{1}$ point to longer ascending aortic graft lengths and use of circulatory arrest during the original operation as major reasons for eligibility for future endovascular repair of the aortic arch. In general, the most common reason given by cardiovascular surgeons for the use of a distal clamp and not an open anastomosis under circulatory arrest for repair of type A aortic dissections is that this operative strategy has been assumed to be safer in the short term; however, the use of circulatory arrest and performing a hemiarch has shown a survival advantage $^{2,3}$ during the original acute operation. So not only does an open anastomosis under circulatory arrest improve initial survival, it could also help lessen the blow of a potential reoperation by making endovascular means amenable.

Another operative choice, which Buditz-Lilly and colleagues ${ }^{1}$ do not mention but should be carefully considered, is the deployment at initial operation of an antegrade stent in the descending thoracic aorta during circulatory arrest. Even beyond the long-term decrease in reoperation shown by a small case series, ${ }^{4}$ the addition of a stable distal landing zone to treat aortic arch pathology may prove useful as technology evolves.

From the Divisions of Cardiovascular and Vascular Surgery, North Central Heart Institute, Sioux Falls, SD.

Disclosures: Authors have nothing to disclose with regard to commercial support. Received for publication Feb 6, 2020; revisions received Feb 6, 2020; accepted for publication Feb 11, 2020; available ahead of print Feb 19, 2020.

Address for reprints: Meghana R.K. Helder, MD, North Central Heart Institute, 4520 W 69th St, Sioux Falls, SD 57108 (E-mail: MHelder@ncheart.com).

J Thorac Cardiovasc Surg 2021;162:778-9

$0022-5223 / \$ 36.00$

Copyright (c) 2020 by The American Association for Thoracic Surgery

https://doi.org/10.1016/j.jtcvs.2020.02.040

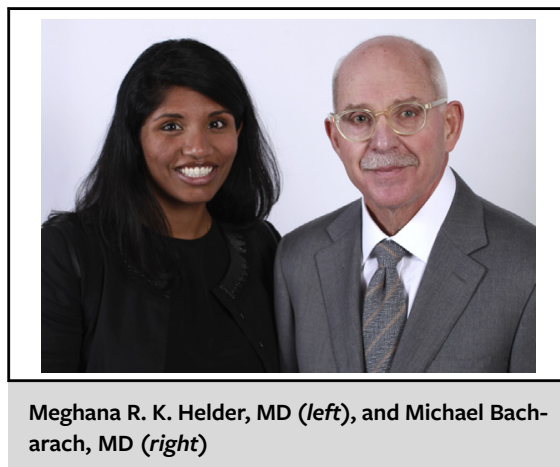

CENTRAL MESSAGE

At operation for type A aortic dissections, longer graft lengths and the use of circulatory arrest not only allow the use of endovascular options for reoperation but improve short-term survival.

Even though Buditz-Lilly and colleagues ${ }^{1}$ are to be commended in taking this first step of determining potential eligibility of endovascular options for reoperative arch repair in dissections, they only look at a single device, the Cook device. They do not evaluate or discuss the Streamliner Multilayer Flow Modulator device ${ }^{5}$ and others similar to it, which would expand the anatomy amenable to endovascular options.

It is easy to understand the appeal of trying to save a patient's life by using the simplest operation available, and in the case of an acute type A aortic dissection, that would be the clamp and sew technique. When there are good reasons founded in the pathophysiology of the disease, however, a change in our operative practice must evolve, and the more complicated operation must be performed. Further, the more complicated operation should be performed not only thinking of the future implications, as Buditz-Lilly and colleagues ${ }^{1}$ point out, but also to give the patient a better chance at survival with this morbid and deadly disease.

\section{References}

1. Buditz-Lilly J, Vikholm P, Wanhainen A, Astudillo R, Thelin S, Mani K. Technical eligibility for endovascular treatment of the aortic arch after open type A aortic dissection repair. J Thorac Cardiovasc Surg. 2021;162:770-7.

2. Helder MRK, Schaff HV, Day CN, Pochettino A, Bagameri G, Greason KL, et al. Regional and temporal trends in the outcomes of repairs for acute type A aortic dissections. Ann Thorac Surg. 2020;109:26-33. 
3. Lawton JS, Liu J, Kulshrestha K, Moon MR, Damiano RJ Jr, Maniar H, et al. The impact of surgical strategy on survival after repair of type A aortic dissection. $J$ Thorac Cardiovasc Surg. 2015;150:294-301.e1.

4. Pochettino A, Brinkman WT, Moeller P, Szeto WY, Moser W, Cornelius K, et al. Antegrade thoracic stent grafting during repair of acute DeBakey I dissection pre- vents development of thoracoabdominal aortic aneurysms. Ann Thorac Surg. 2009:88:482-9; discussion 489-490.

5. Stefanov F, Morris L, Elhelali A, Kavanagh EP, Lundon V, Hynes N, et al. Insights from complex aortic surgery with a Streamliner device for aortic arch repair (STAR). J Thorac Cardiovasc Surg. 2016;152:1309-18.e5.
See Article page 770.

\section{Commentary: Is the time for aortic arch redo-surgery running out?}

\author{
Luca Di Marco, MD, PhD, ${ }^{a}$ Alessandro Leone, $\mathrm{MD},{ }^{\mathrm{a}}$ \\ Antonio Maria Calafiore, $\mathrm{MD},{ }^{\mathrm{b}}$ and \\ Michele Di Mauro, MD, PhD, $\mathrm{MSc}^{c}$
}

Despite the fact that open surgical repair still represents the gold standard treatment for complete aortic arch replacement, it continues to be burdened by high mortality and neurologic complications $(5 \%-23 \%$ and 5\%-18\%, respectively), especially for patients who require redo surgery. ${ }^{1-4}$ Therefore, in the era of endovascular surgery, it is not surprising that hybrid operating rooms, new technologies, approaches, and methods are challenging open surgery, trying to replace it. Less-invasive endovascular procedures, used to treat aortic arch diseases, have clear and undoubted advantages over open surgery, especially in redo cases: (1) re-sternotomy is not required; (2) there is no need for cardiopulmonary bypass; and (3) there is no need for hypothermic circulatory arrest and cerebral protection.

There is no doubt that a patient already treated for acute type A aortic dissection (TAAD) continues to have considerable risk for future aortic reintervention and that resternotomy is associated with increased risk for short- and long-term mortality after proximal aortic repair. ${ }^{5,6}$ In the light of these advantages, it is clear how selected high-risk patients with chronic residual TAAD

\footnotetext{
From the a Cardiac Surgery Unit, Cardio-Thoracic-Vascular Department, S. Orsola Hospital, University of Bologna, Bologna; ${ }^{b}$ Division of Cardiac Surgery, Molise Gemelli, Campobasso; and ${ }^{\mathrm{c}}$ Division of Cardiac Surgery, SS Annunziata Hospital, Chieti, Italy.

Disclosures: Authors have nothing to disclose with regard to commercial support.

Received for publication Feb 12, 2020; accepted for publication Feb 14, 2020; available ahead of print Feb 21, 2020.

Address for reprints: Michele Di Mauro, MD, PhD, MSc, Heart Disease Department, SS Annunziata Hospital, Via dei Vestini, 66100, Chieti, Italy (E-mail: mdimauro1973@gmail.com).

J Thorac Cardiovasc Surg 2021;162:779-80

$0022-5223 / \$ 36.00$

Copyright $(2020$ by The American Association for Thoracic Surgery

https://doi.org/10.1016/j.jtcvs.2020.02.060
}

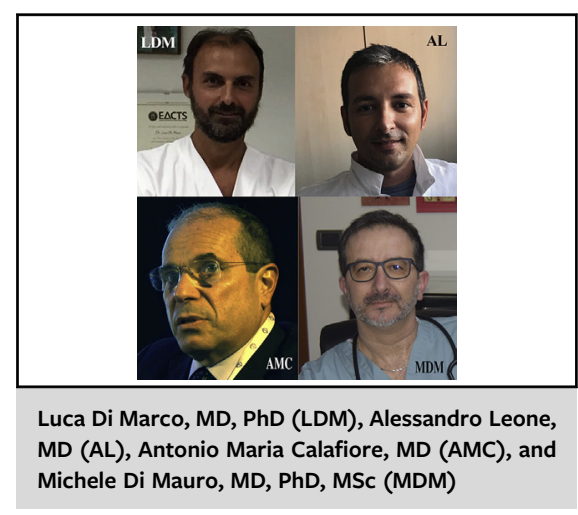

CENTRAL MESSAGE

Is the time for aortic arch redosurgery running out?

could benefit from the endovascular approach, as they often require reoperations to exclude the aortic arch entry tears with consequent enlargement of the pressurized false lumen.

Budtz-Lilly and colleagues ${ }^{7}$ report the current data regarding eligibility for endovascular treatment of dissected aortic arch using an arch inner-branched stent graft, creating the anatomical conditions for a potential further endovascular treatment of the aortic arch and identifying those factors playing a key role in this process. The authors carefully reviewed the angiocomputed tomography scans of the patients operated on for acute TAAD, drawing a picture of eligible candidates for future endovascular arch repair as an alternative to open surgery. Beyond this, the strengths of this study are the very large cohort of patients enrolled, with longer follow-up and the exclusion of those patients with wellknown ineligibility factors such as the presence of a mechanical aortic valve. Another important key point of the study is the different eligibility between those patients in whom distal aortic clamping was used and those in whom 